\title{
Study of phosphorylation events for cancer diagnoses and treatment
}

\author{
Elena López Villar ${ }^{1 *}$, Luis Madero1, Juan A López-Pascual ${ }^{2}$ and William C Cho ${ }^{3^{*}}$
}

\begin{abstract}
The activation of signaling cascades in response to extracellular and intracellular stimuli to control cell growth, proliferation and survival, is orchestrated by protein kinases via phosphorylation. A critical issue is the study of the mechanisms of cancer cells for the development of more effective drugs. With the application of the new proteomic technologies, together with the advancement in the sequencing of the human proteome, patients will therefore be benefited by the discovery of novel therapeutic and/or diagnostic protein targets. Furthermore, the advances in proteomic approaches and the Human Proteome Organization (HUPO) have opened a new door which is helpful in the identification of patients at risk and towards improving current therapies. Modification of the signaling-networks via mutations or abnormal protein expression underlies the cause or consequence of many diseases including cancer. Resulting data is used to reveal connections between genes proteins and compounds and the related molecular pathways for underlining disease states. As a delegate of HUPO, for human proteome on children assays and studies, we, at Hospital Universitario Niño Jesús, are seeking to support the human proteome in this context. Clinical goals have to be clearly established and proteomics experts have to set up the appropriate proteomic strategy, which coupled to bioinformatics will make it possible to achieve new therapies for patients with poor prognosis. We envision to combine our up-coming data to the HUPO organization in order to support international efforts to advance the cure of cancer disease.
\end{abstract}

Keywords: Diagnosis; Oncology; Proteomics; Treatment

\section{Background}

Proteomics is a powerful tool in biomarker discovery and mechanism understanding. Proteomics is the next generation following genomics. Using proteomics, researchers can efficiently perform large-scale screening to achieve valuable information [1].

The Human Proteome Organization (HUPO) main goal is to serve the Public Health Service in an international manner via collaborators from the best expertise and well-known excellence academics. In this context, we would like to point out the important contribution from Spanish Proteomic Society (SeProt), European Proteomic Society (EUPA) and HUPO to obtain the sequence of the human proteome. We aim to contribute with our future data from Hospital Niño Jesus

\footnotetext{
*Correspondence: Elena.lopez.villar@gmail.com; williamcscho@gmail.com Oncohematology of Children Department, Hospital Universitario Infantil Niño Jesús, Av. Menéndez Pelayo 65, Madrid, Spain

${ }^{3}$ Department of Clinical Oncology, Queen Elizabeth Hospital, Hong Kong, China

Full list of author information is available at the end of the article
}

using body fluids (such as bone marrow, peripheral blood) from children suffering cancer, and by collaboration with several international hospitals and research centers of prestige for this important labor, which will benefit children with poor prognoses as at present there is no correct therapy for all types of pediatric cancers [2-5].

As different phosphosites in a protein trigger either protein activation or inactivation; phosphosites can be used for quantification. The high number which can be identified as altered phosphoproteins in a clinical study, implies that many can also be reported with key roles in tumor progression and/or drug resistance. Indeed, when obtaining phosphoproteomics data in clinical research, vast knowledge of drug resistance appear, and thus, new insights are offered for future drug candidates. Several articles show that proteomic analysis is a powerful tool for profiling the phosphorylation patterns and may help to better understand drug resistance [6-11]. We aim to show some proteomic and bioinformatics tools which are useful for clinical research and which contribute 
towards accurate diagnoses and improve therapies in order to benefit the patients.

\section{Findings}

Phosphoproteomics for deciphering drug resistance and new therapies related to phosphorylation pathways in cancer

Our aim is to outline as basic ideas and tools of proteomics, how evolution is aiming to reach clinical advances. Amino acids site-specific phosphorylation assignments on thousands of proteins in a single experiment are possible. The combination of different proteomic-MS strategies is already being carried out to characterize signaling pathways that govern oncogenesis and also to unravel targets of kinase inhibitors, difficult to characterize because of spatial and temporal cellular events. It is, therefore, helpful for understanding cell pathways and facilitating drug discovery [1].

\section{Sample preparation}

The sample preparation step is the key to successful phosphoproteomic-analysis. These include: (a) be snapfrozen; (b) include treatments with phosphatase inhibitors to avoid modifying phosphopeptides during sample work-up; and (c) avoid salts and detergents, which interfere with subsequent analyses. Using Immobilized metal ion affinity chromatography (IMAC), titanium dioxide metal-based chromatography $\left(\mathrm{TiO}_{2}\right)$, zirconium dioxide $\left(\mathrm{ZrO}_{2}\right)$ and sequential elution from IMAC (SIMAC), the negatively charged phosphopeptides are purified by their affinity to positively charged metal ions $[1,8]$.

During IMAC and $\mathrm{TiO}_{2}$ operations, simple and complex samples containing phosphopeptides and nonphosphorylated peptides are dissolved in an acidic solution to reduce the non-specific binding of acidic peptides, and to stimulate the electrostatic interactions between the negatively charged peptides, mainly phosphopeptides, and the metal ions. IMAC mainly elutes multiple-phosphopeptides while $\mathrm{TiO}_{2}$ chiefly elutes mono-phosphopeptides. Both resins have the drawback of binding acidic non-phosphorylated peptides (negatively charged peptides), as peptides containing acidic amino acid residues (e.g. glutamic acid and aspartic acid), can also bind to the metal ions. This drawback on IMAC $\left(\mathrm{Fe}^{3+}\right)$ is circumvented via converting acidic amino acid residues to methyl esters and esterification of the acidic residues prior to the MS analysis. In addition, higher specificity is achieved and yield compared to IMAC $\left(\mathrm{Fe}^{3+}\right)$ for the selective enrichment of phosphorylated peptides from model proteins when using 2,5-dihydroxybenzoic acid (DHB) with $\mathrm{TiO}_{2}$. In fact, more phosphopeptides are bound to the metal ions and more phosphopeptides can be isolated by using ammonium hydroxide as the eluent by use of glycolic acid in the loading buffer of $\mathrm{TiO}_{2}$. SIMAC is the combination of IMAC with $\mathrm{TiO}_{2}$ protocols. It includes improvements in both resins to be coupled in an efficient manner in order to allow enrichment of mono-and multiplephosphorylated peptides in a single experiment. Monophosphorylated peptides mainly elute from IMAC $\left(\mathrm{Fe}^{3+}\right)$ under acidic conditions whereas multi-phosphorylated peptides elute at high basic $\mathrm{pH}$.

$\mathrm{ZrO}_{2}$ is another useful phosphopeptide enrichment prior to MS analysis and its principle is based on metal affinity chromatography such as IMAC and $\mathrm{TiO}_{2}$. The relevant clue related to $\mathrm{ZrO}_{2}$ is that it permits the isolation of single phosphorylated peptides in a more selective manner than $\mathrm{TiO}_{2}$ [12-24]. In addition, purification of phosphorylated proteins can be carried out via antibody-purification. This methodology is highly efficient when purifying tyrosine - phosphorylated proteins, and it can also be coupled to phosphoenrichments such as IMAC, $\mathrm{TiO}_{2}, \mathrm{ZrO}_{2}$ and SIMAC for further MS analysis. This is an important advantage as phosphorylation on tyrosines is under-represented by MS-assays, thus the use of specific antibodies to enrich tyrosine phosphorylated peptides from complex samples is of advantage [25].

When combining the previously mentioned phosphoenrichments with strong cation and anion exchange (SCX and SAX) or hydrophilic interaction chromatography (HILIC), large-scale phosphoproteomic studies of interest can be carried out successfully. During SAX operations, a negatively charged analyte is attracted to a positively charged solid support, and during SCX operations, a positively charged analyte is attracted to a negatively charged solid support. Both techniques were, for the first time, successfully coupled to IMAC, achieving greater recovery and identification by MS of important phosphorylated peptides originating from signalling pathways and membrane proteins respectively, therefore making it possible to carry out relevant scientific studies following those protocols described in the references previously detailed. In addition, today's scientists use these tools to achieve important biological understanding. HILIC is a liquid/liquid extraction method among mobile and stationary phases (polar). On the surface of the stationary phase a water rich layer is obtained. Therefore, distribution of the analytes among these layers occurs. More polar compounds show stronger interaction with the stationary aqueous-layer than less polar compounds, taking place in stronger retention [26-28].

\section{Improvement in methodologies}

Improvement in methodologies to enrich for phosphorylated residues from kinases is clearly necessary for clinical cancer research. This is difficult due to: (1) the low 
abundance of those signalling molecules within cells; (2) the stress/stimulation time-duration, of phosphorylated kinases; (3) the time adaptation over signalling pathways. To overpass this issue, several approaches-combinations can be applied: for example SIMAC coupled to SCX and LC-MSMS. In every case it is always necessary to optimise, by expertise proteomics, the right strategy (several proteomic combined tools) to achieve the clinical goal previously established. In addition, using 'the combination of $\mathrm{C}_{18}-\mathrm{TiO}_{2}-\mathrm{C}_{18}$ chromatography, efficient phosphopeptideloading conditions are increased for clinical samples containing kinases or low expressed proteins and more importantly, "it is without compromise on sample loading or analysis based-times as, it permits the complementary measurement of the enriched phosphopeptides and their non-phosphorylated counterparts in following assays, making for quantitative phosphoproteomics" [29]. In the combination of several phosphoproteomic strategies, signaling aberrant pathways involved in cancer progression can be understood, thus drug resistance can be reduced and therapies can be improved.

\section{Discussion}

Combining phosphoproteomics and bioinformatics for deciphering drug resistance and new therapies related to phosphorylation pathways in cancer

The proteomic community, EUPA and HUPO played very important roles, and today many hospitals are applying those proteomic advances to study the evolution of patients, as by combining proteomics to genomics data, many diseases which were not cured in the past, have now been improved [30, 31].

For example, D'Souza RC et al. [32] coupled assays of changes in protein expression, phosphorylation, protein interactions and transcriptional regulation, allowing a brilliant scheme of the dynamic signaling events underlying TGF- $\beta$-induced changes in cell behavior. Their study evokes that temporal regulation of different proteins could be a mechanism to arbitrate the effects of TGF- $\beta$ in keratinocytes. They also showed that early TGF- $\beta$-signaling is a combination of pro- and antiproliferative molecules. It is known that TGF- $\beta$ signaling actively support cell-motility via the inducing of epithelial to mesenchymal transitions in cancer. Authors carried out time resolved assays of the phosphoproteomic profile of cultured human keratinocytes undergoing epithelial-to mesenchymal transitions and cell cycle arrest as a consequence of stimulation with TGF- $\beta$. They were able to quantify significant changes in around 3,000 phosphorylation sites regulated via TGF- $\beta$. Moreover, following their phosphoproteomic strategy, authors discovered that TGF- $\beta$ induced phosphorylation of AKT and GSK3 $\alpha$. This study explains that the combination of system-level assays with knowledge of specific phosphorylated sites facilitate a deeper understanding of the mechanisms of crosstalk pathways.

Another example shows how phospho-quantitative assays in skin cancer (via SILAC mouse technology coupled to MS) can complement genetic assays, via different states using mouse models. Zanivan et al. [33] carried out phosphoproteomics to get the specific molecules involved in different cancer stages, observing that the cell growth and cell adhesion are altered pathways to driver malignant cells. Moreover authors observed that when coupling phosphoproteomics and prediction of kinase activity, in this research study, PAK4-PKC/SRC network was highly deregulated in SCC although it was not in papilloma. As they said "This detailed molecular picture, both at the proteome and phosphoproteome level, will prove useful for the study of mechanisms of tumor progression".

The importance of the heat shock protein 90 (Hsp90) inhibitors as chemotherapeutic agents in diseases such as cancer is increasing, but their total consequences on the proteome are yet unknown. Sharma et al. [34] via quantitative-MS mapped map protein expression changes associated with the application of the Hsp90 inhibitor, 17-(dimethylaminoethylamino)-17-demethoxygeldanamycin (17-DMAG). In this study, they demonstrated that the activation of a heat shock response with induced expression of molecular chaperones, that re-fold misfolded proteins and proteases, can degrade irreversibly damaged polypeptides. Moreover, they were able to quantify 6,000 proteins in HeLa cells via SILAC. In spite of the high number of substrates related to Hsp90, via bioinformatics, they observed that the preferred ones were proteins related to DNA damage response, and protein kinases, especially tyrosine kinases. In addition, they observed that the inhibition of Hsp90 triggered to $34 \%$ down- and $6 \%$ up-regulation of the phosphoproteome. These assays illustrate the cellular response to Hsp90 inhibition at the proteome level and gives light on the mechanisms via Hsp90 which could be used to target cancer cells.

Rigbolt et al. [35] observed an interaction of DNMTs for early differentiation with the polymerase-associated factor 1- transcriptional elongation complex. It is able to link to DNMT target genes encoding OCT4 and NANOG. Therefore, this assay gives a possible molecular clue for silencing OCT4 and NANOG for differentiation cell step. The authors carried out quantitative proteomic and phosphoproteomic assays of human embryonic stem cells to observe cellular events for differentiation cells. They were able to identify around 7,000 proteins and 24,000 phosphorylation sites. From them, $50 \%$ showed different expression-profiles for differentiation-step. Moreover, they got the phosphoproteome-core of human embryonic stem cells. The proteins which showed different 
phosphorylation-pattern are linked to several kinases, transcription factors and DNA methyltransferases. Thus, this study clearly shows a new molecular-connector for silencing the genes OCT4 and NANOG for differentiation-step.

\section{Phosphorylated peptides/proteins mass spectrometry data need to be validated}

The incapacity to adequately validate MS/MS spectral assignments for each phosphorylated peptide is of importance in relation to the tendency towards massive phosphoproteomic data. If adequately carried out, the assignment of all abundant ions in the spectrum is required for spectral validation. This implies a large time commitment. In order to avoid this drawback, many mass spectrometry laboratories have used other search strategies and statistical methods to make an estimate of false positive identification rates. For phosphoproteomics, statistical validation is of great importance in comparison to the wider field of proteomics, given that each phosphorylation is defined, typically, by a single MS/MS spectrum. Using statistical methods, unfortunately it is not possible to know if any given phosphorylation site is correctly identified, as the MS/MS spectrum is not validated. For biologists with an interest in studying the function of these phosphorylation sites, these false positive identifications are particularly treacherous, due to the fact that the complete investigation of each phosphorylation site may take up to two years. As most biologists do not possess the expertise necessary to assess the accuracy of the assignment even if the raw MS/MS spectrum is provided, the situation worsens, and it is frequently wrongly assumed that all phosphorylation assignments published are correct. Manual validation of the phosphorylated peptides/proteins is, on the other hand, a good challenge, although it implies great expertise with "reading" the spectra [28-35]. In addition, it is essential to get the specific molecules activateddeactivated during cancer evolution of patients, as this implies relevant clues for unraveling good and bad prognoses related to drug resistance and new targettherapies. Phosphoproteomics is a powerful methodology which allows this issue, so that patients will be benefited.

\section{Validation of the phospho data}

Here we would like to describe the manual validation of the phospho data (assignments of the phosphate group on specific amino acids) obtained in an MS experiment during CID (collision-induced dissociation) operations. When peptide ions are fragmented via CID, a series of $\mathrm{y}$ - and $\mathrm{b}$ - ions are formed. The peptide sequence is obtained by correlating the mass difference between peaks in the y-ion series or between peaks in the b-ion series with amino acid residue masses. The CID fragmentation mainly occurs on the peptide backbone, and sequence information is obtained. In relation to phosphotyrosine residues, partial neutral loss is observed $\left(\mathrm{HPO}_{3}, 80 \mathrm{~m} / \mathrm{z}\right)$ in MS2 mode, and the phosphate group on tyrosine (tyr) residues is more stable than on serine (ser) and threonine (thr) residues. In addition, the phospho-finger-print characteristic of phosphotyrosine is the phosphotyrosine immonium ion ( 216 Da). Via MS3 mode, the ion originating from neutral loss (NL) of phosphoric acid $\left(\mathrm{H}_{3} \mathrm{PO}_{4}\right)$ can be selected for further fragmentation. The selected ion is then automatically selected for further fragmentation after neutral loss fragmentation. Therefore, it is possible to add extra energy for the fragmentation of peptide backbone. Nevertheless, the MS3 mode requires that the phosphorylation on ser and thr residues are labile and conventional fragmentation via CID commonly results in the partial NL of $\mathrm{H}_{3} \mathrm{PO}_{4},(98 \mathrm{~m} / \mathrm{z})$ in MS2 mode. This is due to the gas phase $\beta$-elimination of the phosphor-ester bond and thus, dehydroalanine (ser $\sim 69 \mathrm{Da}$ ) and dehydro2-aminobutyric acid (thr $\sim 83 \mathrm{Da}$ ) are generated [36-48].

More importantly, a library-database containing around 5,000 manually validated phosphopeptides product ions and related spectra, from around 330,000 CID fragment spectra analyzed in several LC-MSMS assays from new research studies was created and placed in Sequest (http://fields.scripps.edu/sequest/ index.html) [49] and Mascot (http://www.matrixscience .com) [50-55]. Those CID spectra have been annotated and classified via Sequest and Mascot settings. Those databases apply the filter and search criteria described in their studies. In fact, with relation to the filtering, the resulting spectra data is manually validated via SILVER web application (http://llama.mshri.on.ca/cgi/SILVER/silver.cgi?id=665224) [56].

\section{Validation by bioinformatics softwares}

Laboratories worldwide can now routinely carry out phosphoproteomic assays as owing to the fast improvement of both MS and efficient phosphopeptideenrichments, scientists and clinicians have easy access to lists of thousands of phosphorylated peptides for further biological issues. The application of computational, statistical and predictive analytical methods is vital to answer the biologically relevant questions arising from these phosphor-data $[57,58]$.

It is also possible to carry out the validation more rapidly by bioinformatics software for proteomics assays useful for clinical research. For example, PhosphoSitePlus (http://www.phosphosite.org/homeAction.do) [58] consists of a database with a comprehensive collection of different PTMs including phosphorylation, ubiquitinylation, acetylation and methylation, and it was created by cell signaling technology. From all PTMs, $78 \%$ are phosphorylation, $15 \%$ ubiquitinylation, $6 \%$ acetylation. An 
important feature of PhosphoSitePlus is its ability to generate high-throughput phosphoproteomics data, including both low-throughput and high-throughput experimental data, and rapid sharing of the newly generated data via its website.

On the other hand, The Human Protein Reference Database $[59,60]$ is one of the largest databases for the human proteome (http://www.hprd.org). It includes data from PTMs, sub-cellular localization of human protein, protein-protein interactions, enzyme-substrate relationships, tissue-expression disease-associations all which data is freely downloadable. Also, Phospho. ELM [61-63] (http://phospho.elm.eu.org) mainly contains the collection of manually curated phosphosites and information derived from small-scale experiments. It contains information on around 300 kinases, 8,000 substrates, and over 42,000 phosphosites [63].

\section{Examples of tools for validation potential analysis of the phospho data}

Many computational approaches [64-73] are useful for phosphorylation networks studies of clinical cancer research, or for connecting kinases and phosphosites into a biological signaling network. Bioinformatics tools in this sense, for example, serve to design new drugcandidates from proteomic data. Below are some useful networks for reference.

The STRING-database (http://string-db.org), [64-66] was created to improve and increase the specificity properties from motif-based predictions. In this database there are over 20,000 site-specific interactions available via their website including nearly 4,000 phosphoproteins and 74 human kinases from 20 families and thus, interesting drug-resistances and toxicities studies can be carried out via STRING.

Via NetworKIN (http://www.networkin.info/index. shtml) $[57,68,70]$ network context of kinases and phosphoproteins are incorporated via prediction algorithms. It contains sub-cellular compartmentalization, co-localization via anchoring proteins, scaffolds, temporal and cell-type specific co-expression. The algorithm applies neuralnetworks and position-specific score-matrices in order to assign proper phosphosites to kinases and related families. It consists of intrinsic preference of kinases for consensus of substrate motifs, thus, for example important true biomarkers can be validated coming from proteomics assays.

PANTHER (http://www.pantherdb.org) [71] is focused on inferring the phosphorylation of substrates by corresponding kinases, frequently referred as KSR. Performance of bioinformatics tools to predict binding substrate specificities of protein kinases originated from experimental identification of consensus sequence motifs recognized by the active sites of kinases. It is worth remembering that some phosphorylated residues by different kinases from the CDK and SRC families cannot be distinguished by their consensus sequences alone. Several of these general bioinformatics tools can be applied to capture the evidence and narrow them down to key players in the signaling network. In fact, the signaling network of TBK1- was deciphered as an emerging drug target via phosphoproteomics [64-74]. Authors applied several tools, such as gene ontology (GO) pathway enrichment analysis, motif analysis using the motif- $x$ algorithm [75-77].

Finally, when obtaining data with mutated kinases, clinicians and scientists are interested in knowledge about which kinase-inhibitors can be applied for cancer treatments. Currently, a high-throughput kinase-inhibitor database is accessible, via K-MAP (http://tanlab.ucdenver.edu/ $\mathrm{kMap} / \mathrm{kMapv1.0)}$ [78] and can be used to complement and design future clinical assays to study resistances and toxicities.

There are a number of bioinformatics tools available for biomedical research (Ingenuity Pathway Analysis (www.ingenuity.com) [69], KEGG (http://www.kegg.jp) [70-72], GeneGo metaCore pathway analysis (www.gene go.com) [73], iGPS for systematic analysis of protein phosphorylation networks from phosphoproteomics data; http://igps.biocuckoo.org/index.php) [75, 79], and PostMod for sequence based prediction of kinase-specific phosphorylation sites with indirect relationship (http://pbil.kaist. ac.kr/PostMod) [76] useful and available in specific reviews useful for clinical research. They are currently in use for cancer research and support proteomics to advance the human proteome sequence [77, 78, 80-90].

\section{Conclusion}

With the advances in proteomics and in the near future the completed sequence of the human proteome, we envision we will have a better diagnoses and therapies for the diseases. Today, proteomics is applied in many international hospitals in order to obtain the information about the evolution of patients and obtain specific molecules/sights related to prognoses of various diseases, with benefit for more patients in the coming future.

\section{Competing interests}

The authors declare that they have no competing interests.

\section{Authors' contributions}

ELV, JALP, LM and WCC wrote and approved this manuscript.

\section{Authors' information}

Dr. E. López Villar is supported by Spanish Health System SNS ISCIII-BOE 2012, she is Delegate of HUPO (Human Proteome International Organization) for improvements on diagnoses and therapies for children at Hospital Niño Jesús. JALP is Prof at Quirón Hospital, LM is Prof at Hospital Niño Jesús and WCC is working at Queen Elizabeth Hospital in Hong Kong.

Acknowledgements

This work is supported by Project FIS PI13/02475, ISCIII and Fondos FEDER. 


\section{Author details}

'Oncohematology of Children Department, Hospital Universitario Infantil Niño Jesús, Av. Menéndez Pelayo 65, Madrid, Spain. ²Oncohematology Department, Hospital QUIRÓN Madrid, Madrid, Spain. ${ }^{3}$ Department of Clinical Oncology, Queen Elizabeth Hospital, Hong Kong, China.

Received: 27 April 2015 Accepted: 19 May 2015

Published online: 24 May 2015

\section{References}

1. López E, Madero L, López-Pascual J, Latterich M. Clinical proteomics and Omics clues useful in translational medicine research. Proteome Sci. 2012;9:27.

2. James P. The International Proteomics Tutorial Programme (IPTP): a teaching tool box for the proteomics community. Proteomics. 2011;11(18):3596-7.

3. James P, Marko-Varga GA. The International Proteomics Tutorial Programme-reaching out to the next generation proteome scientists. J Proteome Res. 2011;10(8):3311-2.

4. Dunn MJ, Gil C, Kleinhammer C, Lottspeich F, Pennington S, Sanchez JC, et al. EuPA achieves visibility - an activity report on the first three years. J Proteomics. 2008;71(1):11-8.

5. Orchard S, Albar JP, Binz PA, Kettner C, Jones AR, Salek RM, et al. Meeting new challenges: the 2014 HUPO- PSI/COSMOS workshop: 13-15 April 2014, Frankfurt. Germany Proteomics. 2014;14(21-22):2363-8.

6. Virshup DM, Shenolikar S. From promiscuity to precision: protein phosphatases get a makeover. Mol Cell. 2009;33(5):537-45.

7. Grønborg M, Kristiansen TZ, Stensballe A, Andersen JS, Ohara O, Mann M, et al. A mass spectrometry-based proteomic approach for identification of serine/ threonine-phosphorylated proteins by enrichment with phospho-specific antibodies: identification of a novel protein, Frigg, as a protein kinase A substrate. Mol Cell Proteomics. 2002;1(7):517-27.

8. Zhang ZY. Functional studies of protein tyrosine phosphatases with chemical on different phosphopeptide enrichment techniques. Biochim Biophys Acta. 2005;1754(1-2):100-7.

9. Jensen SS, Larsen MR. Evaluation of the impact of some experimental procedures on different phosphopeptide enrichment techniques. Rapid Commun Mass Spectrom. 2007;21(22):3635-45.

10. Neville DC, Rozanas CR, Price EM, Gruis DB, Verkman AS, Townsend RR Evidence for phosphorylation of serine 753 in CFTR using a novel metal-ion affinity resin and matrix-assisted laser desorption mass spectrometry. Protein Sci. 1997;6(11):2436-45.

11. Figeys D, Gygi SP, McKinnon G, Aebersold R. An integrated microfluidics-tandem mass spectrometry system for automated protein analysis. Anal Chem. 1998:70(18):3728-34.

12. Li S, Dass C. Iron (III)-immobilized metal ion affinity chromatography and mass spectrometry for the purification and characterization of synthetic phosphopeptides. Anal Biochem. 1999;270(1):9-14.

13. Posewitz MC, Tempst P. Immobilized gallium(III) affinity chromatography of phosphopeptides. Anal Chem. 1999;71(14):2883-92.

14. Pinkse MW, Uitto PM, Hilhorst MJ, Ooms B, Heck AJ. Selective isolation at the femtomole level of phosphopeptides from proteolytic digests using 2D-NanoLCESI-MS/MS and titanium oxide precolumns. Anal Chem. 2004;76(14):3935-43.

15. Nuhse TS, Stensballe A, Jensen ON, Peck SC. Large-scale analysis of in vivo phosphorylated membrane proteins by immobilized metal ion affinity chromatography and mass spectrometry. Mol Cell Proteomics. 2003;2(11):1234-43.

16. Ficarro SB, McCleland ML, Stukenberg PT, Burke DJ, Ross MM, Shabanowitz J, et al. Phosphoproteome analysis by mass spectrometry and its application to Saccharomyces cerevisiae. Nat Biotechnol. 2002;20(3):301-5.

17. Larsen MR, Thingholm TE, Jensen ON, Roepstorff $P$, Jørgensen TJ. Highly selective enrichment of phosphorylated peptides from peptide mixtures using titanium dioxide microcolumns. Mol Cell Proteomics. 2005;4(7):873-86.

18. Ashman K, Villar EL. Phosphoproteomics and cancer research. Clin Transl Oncol. 2009;11(6):356-62.

19. López E, Matthiesen R, López I, Ashman K, Mendieta J, Wesselink JJ, et al. Functional phosphoproteomics tools for current immunological disorders research. Journal of Integrated OMICS. 2011;1(1):1-16. doi:10.5584/ jiomics.v1i1.40. http://www.jiomics.com.

20. Connor PA, Dobson KD, McQuillan J. Infrared Spectroscopy of the TiO2/ Aqueous Solution Interface. Langmuir. 1999;15:2402.
21. Connor PA, McQuillan A. Phosphate adsorption onto TiO2 from aqueous solutions: an in situ internal reflection infrared spectroscopic study. Langmuir. 1999;15:2916.

22. Thingholm TE, Jensen ON, Larsen MR. Enrichment and separation of mono- and multiply phosphorylated peptides using sequential elution from IMAC prior to mass spectrometric analysis. Methods Mol Biol. 2009;527:67-78

23. Thingholm TE, Jensen ON, Robinson PJ, Larsen MR. SIMAC (sequential elution from IMAC), a phosphoproteomics strategy for the rapid separation of monophosphorylated from multiply phosphorylated peptides. Mol Cell Proteomics. 2008;7(4):661-71.

24. Kweon HK, Hakansson K. Selective zirconium dioxide-based enrichment of phosphorylated peptides for mass spectrometric analysis. Anal Chem. 2006:78(6):1743-9.

25. Zoumaro-Djayoon AD, Heck AJ, Muñoz J. Targeted analysis of tyrosine phosphorylation by immuno-affinity enrichment of tyrosine phosphorylated peptides prior to mass spectrometric analysis. Methods. 2012;56(2):268-74.

26. Gruhler A, Olsen JV, Mohammed S, Mortensen P, Faergeman NJ, Mann M, et al. Quantitative phosphoproteomics applied to the yeast pheromone signalling pathway. Mol Cell Proteomics. 2005:4(3):310-27.

27. McNulty DE, Annan RS. Hydrophilic interaction chromatography reduces the complexity of the phosphoproteome and improves global phosphopeptide isolation and detection. Mol Cell Proteomics. 2008;7(5):971-80.

28. Elias JE, Haas W, Faherty BK, Gygi SP. Comparative evaluation of mass spectrometry platforms used in large-scale proteomics investigations. Nat Methods. 2005;2:667-75

29. Pinkse MW, Mohammed S, Gouw JW, van Breukelen B, Vos HR, Heck AJ. Highly robust, automated, and sensitive online TiO2-based phosphoproteomics applied to study endogenous phosphorylation in drosophila melanogaster. J Proteome Res. 2008;7(2):687-97.

30. White FM. Quantitative phosphoproteomic analysis of signaling network dynamics. Curr Opin Biotechnol. 2008;19(4):404-9. doi:10.1016/j.copbio.2008.06.006.

31. López Villar E, Wang X, Madero L, Cho WC. Application of oncoproteomics to aberrant signalling networks in changing the treatment paradigm in acute lymphoblastic leukaemia. J Cell Mol Med. 2015;19(1):46-52. doi:10.1111/jcmm.12507.

32. D'Souza RC, Knittle AM, Nagaraj N, van Dinther M, Choudhary C, ten Dijke P, et al. Time-resolved dissection of early phosphoproteome and ensuing proteome changes in response to TGF- $\beta$. Sci Signal. 2014;7(335):rs5. doi:10.1126/scisignal.2004856

33. Zanivan S, Meves A, Behrendt K, Schoof EM, Neilson LJ, Cox J, et al. In vivo SILAC-based proteomics reveals phosphoproteome changes during mouse skin carcinogenesis. Cell Rep. 2013;3(2):552-66. doi:10.1016/ j.celrep.2013.01.003. Epub 2013 Jan 31.

34. Sharma K, Vabulas RM, Macek B, Pinkert S, Cox J, Mann M, et al. Quantitative proteomics reveals that $\mathrm{Hsp} 90$ inhibition preferentially targets kinases and the DNA damage response. Mol Cell Proteomics. 2012;11(3):M111.014654. doi:10.1074/mcp.M111.014654. Epub 2011 Dec 13.

35. Rigbolt KT, Prokhorova TA, Akimov V, Henningsen J, Johansen PT, Kratchmarova I, et al. System-wide temporal characterization of the proteome and phosphoproteome of human embryonic stem cell differentiation. Sci Signal. 2011;4(164):rs3. doi:10.1126/scisignal.2001570.

36. Biemann K. Contributions of mass spectrometry to peptide and protein structure. Biomed Environ Mass Spectrom. 1988;16(1-12):99-111.

37. Roepstorff P, Fohlman J. Proposal for a common nomenclature for sequence ions in mass spectra of peptides. Biomed Mass Spectrom. 1984;11(11):601.

38. Steen H, Küster B, Mann M. Quadrupole time-of-flight versus triplequadrupole mass spectrometry for the determination of phosphopeptides by precursor ion scanning. J Mass Spectrom. 2001;36(7):782-90.

39. Steen $H$, Mann M. A new derivatization strategy for the analysis of phosphopeptides by precursor ion scanning in positive ion mode. J Am Soc Mass Spectrom. 2002;13(8):996-1003.

40. Wiśniewski JR, Mann M. Consecutive proteolytic digestion in an enzyme reactor increases depth of proteomic and phosphoproteomic analysis. Anal Chem. 2012:84(6):2631-7.

41. Choudhary C, Mann M. Decoding signalling networks by mass spectrometry-based proteomics. Nat Rev Mol Cell Biol. 2010;11(6):427-39. doi:10.1038/nrm2900. Epub 2010 May 12. Review. 
42. López E, Wang X, Madero L, López-Pascual J, Latterich M. Functional phosphoproteomic mass spectrometry-based approaches. Clin Transl Med. 2012;1(1):20.

43. López E, Muñoz SR, Pascual UL, Madero L. Relevant phosphoproteomic and mass spectrometry: approaches useful in clinical research. Clin Transl Med. 2012;1(1):2.

44. López E, Cho WC. Phosphoproteomics and lung cancer research. Int J Mol Sci. 2012;13(10):12287-314.

45. López E, Wesselink JJ, López I, Mendieta J, Gómez-Puertas P, Muñoz SR. Technical phosphoproteomic and bioinformatic tools useful in cancer research. J Clin Bioinforma. 2011;1:26.

46. Lopez Villar E and Chi-Shing Cho W. Chapter book, Bioinformatics of Human Proteomics; By Xiangdong Wang; Ed 2013; Springer Science \& Business Media.; (https://books.google.es/books?id=pSRGAAAAQBAJ\&pg= PA75\&dq=Elena+Lopez+Villar\&hl=en\&sa=X\&ei=XOgiVYrsPIHOUvSmg6gL\& ved=0CCEQ6AEwAA\#v=onepage\&q=Elena\%20Lopez\%20Villar\&f=false; clintransmed.com)

47. Lopez E, Madero L, Lopez Pascual J and Latterich M. Omics in Clinical Practice: Genomics, Pharmacogenomics, Proteomics, and edited by Yu Liu; Chapter book Ed Science CRC Press 2014; (https://books.google.es/ books?id=4eTMAwAAQBAJ\&pg=PA137\&lpg=PA137\&dq=elena+lopez+luis +madero+martin+latterich\&source=bl\&ots=Xzrw7g_Zj4\&sig=t5Z1g4Ex5N9 |hj27cqz40ATEDM0\&hl=en\&sa=X\&ei=XU6hVMHTIlvkaL_pglgC\&ved=0CD IQ6AEwBQ\#v=onepage\&q=elena\%20lopez\%20luis\%20madero\%20martin\% 20latterich\&f=false. clintransmed.com)

48. Thingholm TE. Stem cells and phosphorylation. Master Thesis, PR Group, Odense University, University Southern of Denmark. 2005(1): 1-195 (http://www.sdu.dk/bmb).

49. Eng JK, McCormack AL, Yates JR. An approach to correlate tandem mass spectral data of peptides with amino acid sequences in a protein database. J Am Soc Mass Spectrom. 1994;5(11):976-89.

50. Perkins DN, Pappin DJ, Creasy DM, Cottrell JS. Probability-based protein identification by searching sequence databases using mass spectrometry data. Electrophoresis. 1999;20(18):3551-67.

51. Koenig T, Menze BH, Kirchner M, Monigatti F, Parker KC, Patterson T, et al. Robust prediction of the MASCOT score for an improved quality assessment in mass spectrometric proteomics. J Proteome Res. 2008;7(9):3708-17. 46.

52. Pappin DJ, Hojrup P, Bleasby AJ. Rapid identification of proteins by peptide-mass fingerprinting. Curr Biol. 1993;3(6):327-32.

53. Bradshaw RA, Burlingame AL, Carr S, Aebersold R. Reporting protein identification data: the next generation of guidelines. Mol Cell Proteomics. 2006:5(5):787-8.

54. Chamrad D, Meyer HE. Valid data from large-scale proteomics studies. Nat Methods. 2005;2(9):647-8.

55. Wang G, Wu WW, Zhang Z, Masilamani S, Shen RF. Decoy methods for assessing false positives and false discovery rates in shotgun proteomics. Anal Chem. 2009;81(1):146-59.

56. Gibbons FD, Elias JE, Gygi SP, Roth FP. SILVER helps assign peptides to tandem mass spectra using intensity-based scoring. J Am Soc Mass Spectrom. 2004;15(6):910-2.

57. Bennetzen MV, Cox J, Mann M, Andersen JS. PhosphoSiteAnalyzer: a bioinformatic platform for deciphering phospho proteomes using kinase predictions retrieved from NetworkIN. J Proteome Res. 2012;11(6):3480-6. doi:10.1021/pr300016e. Epub 2012 May 23.

58. Hornbeck PV, Zhang B, Murray B, Kornhauser JM, Latham V, Skrzypek E. PhosphoSitePlus, 2014: mutations. PTMs and recalibrations Nucleic Acids Res. 2015;43(Database issue):D512-20. doi:10.1093/nar/gku1267.

59. Muthusamy B, Thomas JK, Prasad TS, Pandey A. Access guide to human proteinpedia. Curr Protoc Bioinformatics. 2013;Chapter 1:Unit 1.21. doi:10.1002/0471250953.bi0121s41.

60. Keshava Prasad TS, Goel R, Kandasamy K, Keerthikumar S, Kumar S, Mathivanan S, et al. Human protein reference database-2009 update. Nucleic Acids Res. 2009;37(Database issue):D767-72. doi:10.1093/nar/gkn892.

61. Dinkel H, Chica C, Via A, Gould CM, Jensen LJ, Gibson TJ, et al. Phospho. ELM: a database of phosphorylation sites-update 2011. Nucleic Acids Res. 2011;39(Database issue):D261-7. doi:10.1093/nar/gkq1104.

62. Diella F, Gould CM, Chica C, Via A, Gibson TJ. Phospho. ELM: a database of phosphorylation sites-update 2008. Phospho. ELM: a database of phosphorylation sites-update 2008. Nucleic Acids Res. 2008;36 (Database issue):D240-4.
63. Diella F, Cameron S, Gemünd C, Linding R, Via A, Kuster B, et al. Phospho. ELM: a database of experimentally verified phosphorylation sites in eukaryoticproteins. BMC Bioinformatics. 2004;5:79.

64. Szklarczyk D, Franceschini A, Wyder S, Forslund K, Heller D, Huerta-Cepas J, et al. STRING v10: protein-protein interaction networks, integrated over the tree of life. Nucleic Acids Res. 2015;43(Database issue):D447-52.

65. Franceschini A, Szklarczyk D, Frankild S, Kuhn M, Simonovic M, Roth A, et al. STRING v9.1: protein-protein interaction networks, with increased coverage and integration. Nucleic Acids Res. 2013;41 (Database issue):D808-15.

66. Szklarczyk D, Franceschini A, Kuhn M, Simonovic M, Roth A, Minguez P, et al. The STRING database in 2011: functional interaction networks of proteins, globally integrated and scored. Nucleic Acids Res. 2011;39(Database issue):D561-8. doi:10.1093/nar/gkq973.

67. Chen YA, Eschrich SA. Computational methods and opportunities for phosphorylation network medicine. Transl Cancer Res. 2014;3(3):266-78.

68. Linding R, Jensen LJ, Pasculescu A, Olhovsky M, Colwill K, Bork P, et al. NetworkIN: a resource for exploring cellular phosphorylation networks. Nucleic Acids Res. 2008;36(Database issue):D695-9.

69. Krämer A, Green J, Pollard Jr J, Tugendreich S. Causal analysis approaches in ingenuity pathway analysis. Bioinformatics. 2014;30(4):523-30. doi:10.1093/bioinformatics/btt703.

70. Horn H, Schoof EM, Kim J, Robin X, Miller ML, Diella F, et al. KinomeXplorer: an integrated platform for kinome biology studies. Nat Methods. 2014;11(6):603-4. doi:10.1038/nmeth.2968.

71. Mi H, Dong Q, Muruganujan A, Gaudet P, Lewis S, Thomas PD. PANTHER version 7: improved phylogenetic trees, orthologs and collaboration with the Gene Ontology Consortium. Nucleic Acids Res. 2010;38(Database issue):D204-10. doi:10.1093/nar/gkp1019.

72. Mann M, Nahar F, Schnorr N, Backofen R, Stadler PF, Flamm C. Atom mapping with constraint programming. Algorithms Mol Biol. 2014;9(1):23.

73. Remily-Wood ER, Liu RZ, Xiang Y, Chen Y, Thomas CE, Rajyaguru N, et al. A database of reaction monitoring mass spectrometry assays for elucidating therapeutic response in cancer. Proteomics Clin Appl. 2011;5(7-8):383-96. doi:10.1002/prca.201000115.

74. Dezso Z, Nikolsky Y, Nikolskaya T, Miller J, Cherba D, Webb C, et al. Identifying disease-specific genes based on their topological significance in protein networks. BMC Syst Biol. 2009;3:36. doi:10.1186/1752-0509-3-36.

75. Mao Y, Van Auken K, Li D, Arighi CN, McQuilton P, Hayman GT, et al. Overview of the gene ontology task at BioCreative IV. Database (Oxford). 2014;2014;

76. Jung I, Matsuyama A, Yoshida M, Kim D. PostMod: sequence based prediction of kinase specific phosphorylation sites with indirectrelationship. BMC Bioinformatics. 2010;11 Suppl 1:S10. doi:10.1186/1471-2105-11-S1-S10.

77. Tiirikka T, Siermala M, Vihinen M. Clustering of gene ontology terms in genomes. Gene. 2014;550(2):155-64. doi:10.1016/j.gene.2014.06.060.

78. Kim J, Yoo M, Kang J, Tan AC. K-Map: connecting kinases with therapeutics for drug repurposing and development. Hum Genomics. 2013;7:20. doi:10.1186/1479-7364-7-20.

79. Song C, Ye M, Liu Z, Cheng H, Jiang X, Han G, et al. Systematic analysis of protein phosphorylation networks from phosphoproteomic data. Mol Cell Proteomics. 2012;11(10):1070-83. Epub 2012 Jul 13.

80. Linding R, Jensen $L J$, Ostheimer GJ, van Vugt MA, Jørgensen C, Miron IM, et al. Systematic discovery of in vivo phosphorylation networks. Cell. 2007;129(7):1415-26.

81. Su MG, Lee TY. Incorporating substrate sequence motifs and spatial amino acid composition to identify kinase-specific phosphorylation sites on protein three-dimensional structures. BMC Bioinformatics. 2013;14(16):S2. doi:10.1186/1471-2105-14-S16-S2.

82. Qin T, Tsoi LC, Sims KJ, Lu X, Zheng WJ. Signaling network prediction by the Ontology Fingerprint enhanced Bayesian network. BMC Syst Biol. 2012; 6 Suppl 3:S3. doi:10.1186/1752-0509-6-S3-S3.

83. Lin J, Xie Z, Zhu H, Qian J. Understanding protein phosphorylation on a systems level. Brief Funct Genomics. 2010;9(1):32-42.

84. Lee TY, Bo-Kai Hsu J, Chang WC, Huang HD. RegPhos: a system to explore the protein kinase-substrate phosphorylation network inhumans. Nucleic Acids Res. 2011;39(Database issue):D777-87.

85. Pei B, Shin DG. Reconstruction of biological networks by incorporating prior knowledge into Bayesiannetwork models. J Comput Biol. 2012;19(12):1324-34 
86. Chen T, Zhao J, Ma J, Zhu Y. Web resources for mass spectrometry-based proteomics. Genomics Proteomics Bioinformatics. 2015;13(1):36-9. doi:10.1016/j.gpb.2015.01.004. Epub 2015 Feb 23.

87. Colangelo CM, Shifman M, Cheung KH, Stone KL, Carriero NJ, Gulcicek EE, et al. YPED: an integrated bioinformatics suite and database for mass spectrometry-based proteomics research. Genomics Proteomics Bioinformatics. 2015;13(1):25-35.

88. Lopez Villar E, Martos-Moreno GA, Chowen JA, Okada S, Kopchick JJ, Argente J. A proteomic approach to obesity and type 2 diabetes. J Cell Mol Med. 2015; doi:10.1111/jcmm.12600

89. López Villar E, Wu D, Cho WC, Madero L, Wang X. Proteomics-based discovery of biomarkers for paediatric acute lymphoblastic leukaemia: challenges and opportunities. J Cell Mol Med. 2014;18(7):1239-46.

90. Lopez E, Lopez Pascual JA, Sequi J. Important clues of current phosphoproteomic approaches for clinical research. J Clin Immunol. 2012;02(S5):1-5.

Submit your manuscript to a SpringerOpen ${ }^{\circ}$ journal and benefit from:

- Convenient online submission

- Rigorous peer review

- Immediate publication on acceptance

- Open access: articles freely available online

- High visibility within the field

- Retaining the copyright to your article

Submit your next manuscript at $\gg$ springeropen.com 